\title{
Erratum to: A soil-plant-atmosphere continuum (SPAC) model for simulating tree transpiration with a soil multi-compartment solution
}

\author{
Omar García-Tejera • Álvaro López-Bernal • \\ Luca Testi • Francisco J. Villalobos
}

Published online: 6 June 2017

C Springer International Publishing Switzerland 2017

\section{Erratum to: Plant Soil (2017) 412:215-233 DOI: 10.1007/s11104-016-3049-0}

The published article has an error in equation 14 in the main text and in equations S34 and S35 in the supplementary materials. These are typing errors generated during the transcription of the equations from the original code and in no way they alter the result of the simulations or the conclusions of the paper since it was carefully checked that all the equations were correctly implemented in the software code.

Finally, in the main text, from equation 5 to the end of the conclusions the references to the equations has to be increased in two numbers. For example when it is said: "Once that the total resistance from root and soil are derived using equations $\mathbf{2}$ and 3" it should say "Once that the total resistance from root and soil are derived using equations $\mathbf{4}$ and $\mathbf{5}$ "

The online version of the original article can be found at http:// dx.doi.org/10.1007/s11104-016-3049-0

O. García-Tejera $(\bowtie) \cdot$ L. Testi $\cdot$ F. J. Villalobos Instituto de Agricultura Sostenible - CSIC, Apartado 4084, 14080 Córdoba, Spain

e-mail: ogarcia@ias.csic.es

Á. López-Bernal · F. J. Villalobos

Departamento de Agronomía, Universidad de Córdoba, Apartado 3048, 14080 Córdoba, Spain
The correct equations are:

Equation 14 and S35

$\psi_{l}=\frac{\sum \frac{\psi_{s i, j}}{R_{s i, j}+R_{r i, j}}}{\sum \frac{1}{R_{s i, j}+R_{r i, j}}}-g_{c 02 s u n} 1.6 \frac{V P D}{P} 0.018\left(\frac{\sum \frac{1}{\frac{1}{R_{s i, j}+R_{r i, j}}}+R_{x}}{f_{s u n}}\right) L A I_{s u n}$

Equation S34

$\psi_{l}=\frac{\sum \frac{\psi_{s i, j}}{R_{s i, j}+R_{r i, j}}}{\sum \frac{1}{R_{s i, j}+R_{r i, j}}}-E p\left(\frac{1}{\sum \frac{1}{R_{s i, j}+R_{r i, j}}}+R_{x}\right)$

Personally and on behalf of my co-authors, I express my sincere regrets for the inconveniences we may cause. 